\title{
Avaliação da Resina Epóxi Aplicada em Revestimento para Tubulações Aço-Carbono Expostos em Água Produzida na Produção de Petróleo
}

\author{
Helmut Piper, Josiane D. V. Barbosa, \\ Joyce B. Azevedo \& Pollyana S. M. Cardoso
}

Dutos de transporte utilizados por petroquímicas apresentam problemas de corrosão e os revestimentos a base de epóxi são opções para diminuir estes efeitos. Neste trabalho, foram analisadas amostras de revestimentos a base de epóxi em duas formas distintas: pó e componente líquido. A preparação das amostras seguiu a norma ASTM D 4417 e foram submetidas a ensaios de arrancamento e caracterização térmica por Calorimetria Exploratória Diferencial (DSC) e Termogravimetria (TG). Para aproximar os ensaios da aplicação em campo, foram realizados testes de exposição das amostras em água produzida na produção de petróleo. Os testes em água produzida em petróleo mostraram que os revestimentos não são eficientes neste ambiente. A caracterização térmica indicou que o revestimento na forma em pó apresenta maior estabilidade térmica.

Palavras-chave: epóxi; revestimento; propriedades térmicas; adesão.

Transport pipelines used by petrochemicals have corrosion problems and epoxy coatings are options to reduce these effects. In this work, samples of epoxy coatings in two different forms were analyzed: powder and liquid component. Sample preparation followed the ASTM D 4417 standard and were subjected to pullout tests and thermal characterization by Differential Scanning Calorimetry (DSC) and Thermogravimetry (TG). To approximate the tests of application in the field, tests of exposure of the samples in water produced in the production of oil were carried out. Tests on oil-produced water have shown that coatings are not efficient in this environment. The thermal characterization indicated that the coating in powder form has greater thermal stability.

Keywords: epoxy; coating; thermal properties; adhesion. 


\section{Introdução}

Historicamente as indústrias químicas sofrem com a degradação acelerada de seus equipamentos e estruturas metálicas, sendo a corrosão a principal responsável. A utilização de insumos oxidantes é um dos principais fatores para o início e intensificação dos processos corrosivos. Assim, a corrosão é um dos maiores desafios enfrentados pelas indústrias químicas de todo mundo ${ }^{1}$.

Estudos realizados em empresas no setor petroquímico têm mostrado que os dutos de transporte em atividade no país apresentam sérios problemas de corrosão interna e formação de depósitos, tanto orgânicos como inorgânicos. A extensão e gravidade destes problemas estão relacionadas ao tipo de produto transportado, condições de operação e localização, implicando em manutenção periódica dos mesmos e causando sérios prejuízos, tanto do ponto de vista do processo em si, como pela necessidade de interrupção de atividade ${ }^{2}$.

Para diminuir os efeitos da corrosão em dutos, optou-se até recentemente pela utilização de tubulações de ligas de aços especiais ou ligas de aços inoxidáveis. No entanto, está ainda é uma solução cara e um dos desafios é buscar alternativas para substituir a utilização destes componentes e reduzir custos. Novas alternativas para especificação de tubulações estão sendo adotadas, principalmente utilizando tubulações de aço carbono com revestimentos internos ${ }^{3}$.

Diversos tipos de revestimentos estão sendo propostos, entre eles, o uso de revestimentos orgânicos é uma das abordagens mais importantes para minimizar a enorme perda por corrosão. Os revestimentos internos a base de epóxi, principalmente devido ao seu baixo custo, facilidade de aplicação e alta resistência a corrosão, está entre as principais opções de revestimentos internos de tubulações ${ }^{4-5}$.

Para o uso em revestimento interno de dutos é bastante comum utilizar a resina a base de Bisfenol F, também conhecida comercialmente como Novolac. Esta resina apresenta reticulações na sua estrutura o que proporciona maior resistência térmica, química e elevada dureza ${ }^{6}$. Esta resina, quando aplicada em tubulações internas, pode ser aplicada por dois métodos. Os mais utilizados oferecidos pelas empresas que prestam esses serviços realizam a aplicação em oficina apropriada utilizando: jateamento, pré-aquecimento, aplicação do epóxi em pó através de deposição eletrostática e cura em estufa e em caso de reparo a opção in loco, que é a aplicação manual de epóxi líquido junto com catalisador.

Muitos estudos avaliam o efeito do epóxi como revestimento, no entanto, não encontra-se na literatura estudos comparativos entre as formas de aplicação desta resina ${ }^{2,7-11}$. Sendo assim, este trabalho teve como objetivo avaliar a aderência e propriedades térmicas de revestimentos orgânicos a base de epóxi em tubulações de aço carbono utilizadas na indústria do petróleo utilizando duas formas de aplicação.

Estes revestimentos também foram avaliados em ambiente relevante, para tanto realizou-se teste de exposição das amostras em água produzida. A água é um subproduto da produção do petróleo e gás gerado durante o processo de separação. Esta água aprisionada nas formações subterrâneas é trazida à superfície, durante as atividades de produção, juntamente com o petróleo e o gás extraídos. Entre os aspectos que se destacam está a complexidade da sua composição e seus elevados volumes produzidos ${ }^{12-13}$.

Conforme Thomas et al., ${ }^{14}$ a água produzida associada à extração de petróleo pode ter origem em acumulações de água, chamadas de aquíferos, que podem estar adjacentes às formações portadoras de hidrocarbonetos ou pode ser devida à água injetada em projetos que visam aumentar a recuperação de óleo. A qualidade da água produzida está intimamente ligada a composição do petróleo, sendo que os principais compostos constituintes são óleo, minerais e gases dissolvidos da formação geológica, compostos químicos residuais da produção, sólidos da produção, e microrganismos ${ }^{15}$. 


\section{Metodologia}

\section{MATERIAIS}

Para realização dos recobrimentos foi utilizada uma resina epóxi do tipo Bisfenol $\mathrm{F}$ de nome comercial Novolac IPC ME-35, fornecida pela Empresa Nova Coating. Segundo o fabricante, está resina é recomendada para aplicações onde se tem alta temperatura e pressão, na presença de $\mathrm{H}_{2} \mathrm{~S}, \mathrm{CO}_{2}$, $\mathrm{CH}_{4}$, petróleo bruto, água do mar, salmoura, óleo de malas e ácidos utilizado para operações de perfuração ${ }^{16}$. Esta resina foi utilizada na forma líquida e em pó.

\section{PREPARAÇ̃̃O DAS AMOSTRAS}

Foram confeccionados corpos de prova com aço-carbono 1020 e dimensões $80 \times 80 \times 3,2 \mathrm{~mm}$. Para aplicação do revestimento, as superfícies dos corpos de prova foram descontaminadas através de jateamento com grau de limpeza As $21 / 2$, conforme norma NACE $\mathrm{N}^{\circ} 2 / \mathrm{SSPC}-\mathrm{SP} 10^{17}$. Antes da aplicação dos revestimentos, os corpos de prova foram inspecionados quanto a presença de escorias de soldagem e defeitos de fabricação.

Para as amostras onde foi realizado o revestimento com epóxi em pó, foi necessário um pré-aquecimento até $100^{\circ} \mathrm{C}$ e então o coating foi aplicado manualmente. A aplicação foi executada em 5 corpos de prova através de uma pistola utilizada para aplicação manual do pó eletrostaticamente sobre a peça aquecida. Logo após aplicação as peças foram curadas em estufa por 24 horas a $100^{\circ} \mathrm{C}$. Nas amostras onde foi utilizado o epóxi líquido, o coating também foi aplicado manualmente em 5 corpos de prova e logo após aplicação, as peças foram para cura na temperatura ambiente por 24 horas.

\section{EXPOSIÇÃO DAS AMOSTRAS EM ÁGUA PRODUZIDA}

Para avaliar o comportamento do revestimento, em condições similares a realidade de aplicação, foi realizado um teste de longa duração a exposição em água produzida.
A água produzida utilizada neste estudo foi obtida de um poço de produção de petróleo na região do Recôncavo da Bahia. Antes da exposição das amostras foram realizadas análises físico-química e química da água produzida. Para a determinação do pH utilizou-se o método EN029 QGI, os cloretos e sulfatos foram determinados pelo método EN 138 QGI (EPA 300.1-1); o Bário, Cálcio, Ferro e Sódio foram determinados pelo método EN 301 ESP(EPA6010B/3010A); a alcalinidade total por EM 003 QGI (SMEWW 2320A/B); para salinidade utilizou-se EN 151 QGI e para os sulfetos o método EN 155 QGI (SMEWW 4500- S F).
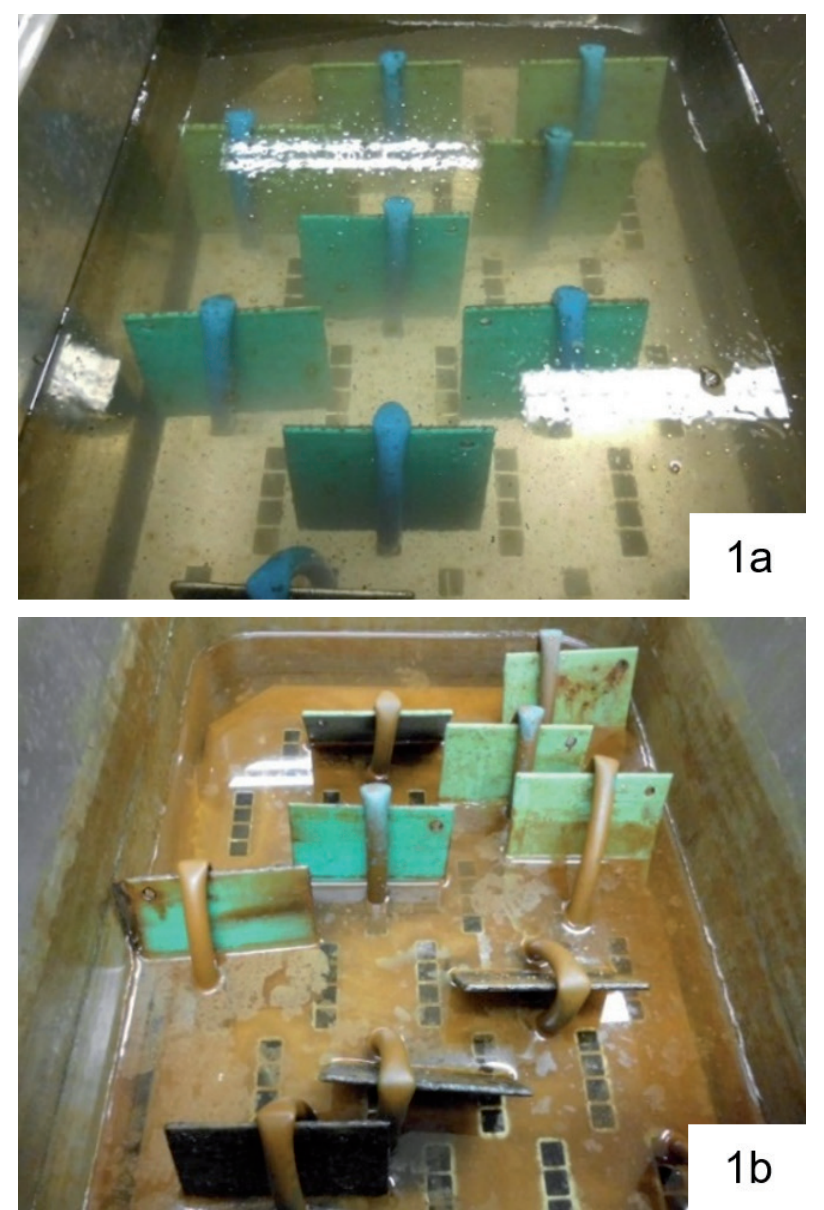

Figura 1: Amostras revestidas com epóxi em submersas em água produzida. (a) Início da exposição; (b) Após 30 dias de exposição. 
As amostras, com recobrimento de epóxi liquido e em pó, foram totalmente submersas na água produzida em equipamento de banho Maria micro processado, da marca Quimis, modelo 6215M2 (Figura 1). Utilizouse uma temperatura de $90^{\circ} \mathrm{C}$ durante 12 horas e então a água produzida foi resfriada durante as próximas 12 horas. Este ciclo foi reproduzido durante 30 dias.

\section{ENSAIO DE ADESÃO}

A adesão dos revestimentos foi caracterizada pelo ensaio de pull-off. A análise foi realizada nas amostras, sem e com exposição à água produzida nas duas formas de epóxi (líquido e em pó). Neste ensaio, realizado conforme norma ASTM D $4541{ }^{18}$, é possível mensurar a tensão de ruptura da interface formada entre as superfícies. As amostras foram submetidas ao ensaio em uma máquina universal de ensaio da EMIC modelo DL2000, com velocidade de $2 \mathrm{~mm} / \mathrm{min}$.

\section{CARACTERIZAÇÃO TÉRMICA}

A caracterização térmica dos revestimentos, antes da exposição à água produzida, foi realizada através de calorimetria exploratória diferencial (DSC) e termogravimetria (TGA). Da superfície dos corpos de prova foram retiradas amostras dos tipos de epóxi estudados.

Os testes de Calorimetria Exploratória Diferencial (DSC) foram realizados em equipamento da NETZSCH modelo: DSC 200F3, com taxa de aquecimento de $20^{\circ} \mathrm{C} / \mathrm{min}$ até alcançarem $590^{\circ} \mathrm{C}$ e resfriados com taxa de $10^{\circ} \mathrm{C} / \mathrm{min}$ até $30^{\circ} \mathrm{C}$. Os testes de análise termogravimétrica (TGA) foram realizados em analisador térmico da Shimadzu modelo: TGA-50H, com razão de aquecimento de $10^{\circ} \mathrm{C} / \mathrm{min}$, atmosfera de nitrogênio com vazão do gás de $100 \mathrm{~mL} / \mathrm{min}$ e faixa de temperatura do ensaio de $25-1000^{\circ} \mathrm{C}$.

\section{Resultados}

\section{ANÁLISE FÍSICO-QUÍMICA E QUÍMICA DA ÁGUA PRODUZIDA}

A Tabela 1 apresenta os resultados da análise da água produzida.

Tabela 1: Análise físico-química e química da água produzida

\begin{tabular}{|c|c|}
\hline Ensaio & Resultado \\
\hline $\mathrm{pH}$ & 6,65 \\
\hline Cloretos & $20800 \mathrm{mg} / \mathrm{L}$ \\
\hline Sulfatos & $50,6 \mathrm{mg} / \mathrm{L}$ \\
\hline Bário (Ba) total & $13,7 \mathrm{mg} / \mathrm{L}$ \\
\hline Cálcio (Ca) total & $3330 \mathrm{mg} / \mathrm{L}$ \\
\hline Ferro (Fe) total & $19,8 \mathrm{mg} / \mathrm{L}$ \\
\hline Sódio (Na) total & $12300 \mathrm{mg} / \mathrm{L}$ \\
\hline Alcalinidade total & $195 \mathrm{mg} / \mathrm{L} \mathrm{CaCO} 3$ \\
\hline Salinidade & $<0,1 / 0,1$ \\
\hline Sulfetos & $<0,04 \mathrm{mg} / \mathrm{L}$ \\
\hline
\end{tabular}

A composição da água produzida é complexa e variada, sua qualidade depende da composição do petróleo, sendo que os principais componentes são óleo, minerais dissolvidos da formação, compostos químicos residuais de produção, sólidos da produção, gases dissolvidos e microrganismos ${ }^{19}$. Sendo que a corrosão está associada aos cloretos e a incrustação aos sulfatos e carbonatos ${ }^{20}$.

A água produzida utilizada neste estudo apresentou os valores de $\mathrm{pH}$ de 6,65, sendo este classificado como ácido, uma grande quantidade de Cloretos $20800 \mathrm{mg} / \mathrm{L}$, e os Sulfatos com 50,6 mg/L, valores que contribuem para a corrosão ${ }^{19-22}$.

Ressalta-se a importância da caracterização da água produzida utilizada considerando-se os objetivos do estudo e os parâmetros físico-químicos que influenciam no processo de corrosão dos tubos recobertos aos quais foram avaliados. A obtenção de uma estimativa real do $\mathrm{pH}$ na fase de água é um dos aspectos mais importantes na avaliação de corrosão de poços de petróleo e gás. Para os casos com apenas água condensada esta deve incluir uma avaliação do aumento do $\mathrm{pH}$ da água de condensação, devido ao 
bicarbonato produzido pela corrosão. A química da água e, portanto, o $\mathrm{pH}$ resultante pode alterar consideravelmente a taxa de corrosão ${ }^{21}$.

Segundo Henriques ${ }^{3}$, a presença de cloretos na água produzida provoca a corrosão interna de tubulações e equipamentos de processo. O mecanismo de corrosão ocorre principalmente pela ruptura do filme passivo pelo íon cloreto $\left(\mathrm{Cl}^{-}\right)$, provocando pites, alvéolos ou pequenas cavidades.

\section{ENSAIO DE ADESÃO}

A Figura 2 apresenta os resultados de tensão de ruptura (pull-off) obtidos no ensaio para avaliação da resistência de aderência a tração das amostras revestidas com epóxi em pó e na forma líquida, antes e após exposição à água de produção.

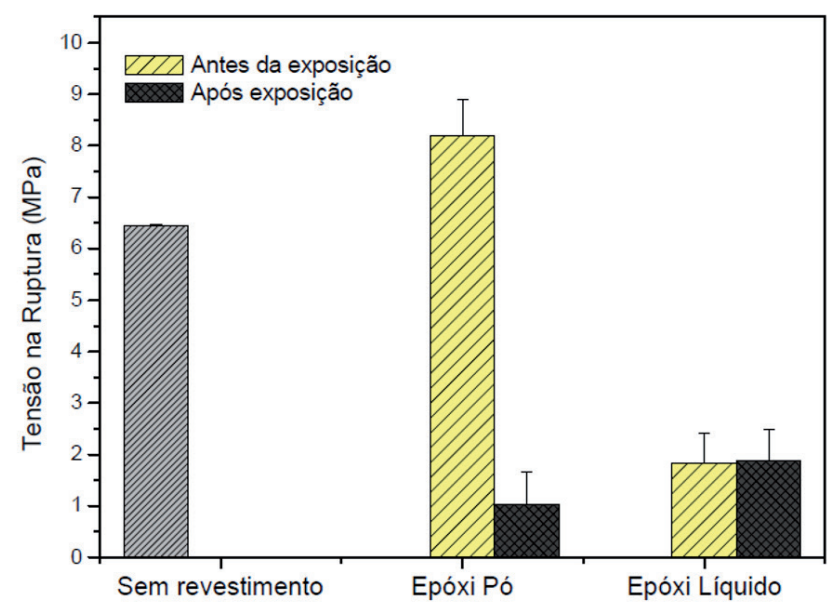

Figura 2: Tensão de ruptura (pull-off) das amostras com revestimentos epóxi antes e após exposição.

As amostras revestidas com epóxi em pó antes da exposição na água produzida apresentaram melhores resultados quando comparadas as demais. A presença do revestimento em pó aumentou em aproximadamente $21,4 \%$ a tensão de pull-off quando comparada a amostra sem revestimento. No entanto, o mesmo resultado não foi observado para a amostra com o revestimento líquido. Nestas amostras verifica-se uma queda significativa quando comparada as demais, possivelmente pelo efeito degradativo que o ambiente com água produzida causou nestas amostras.
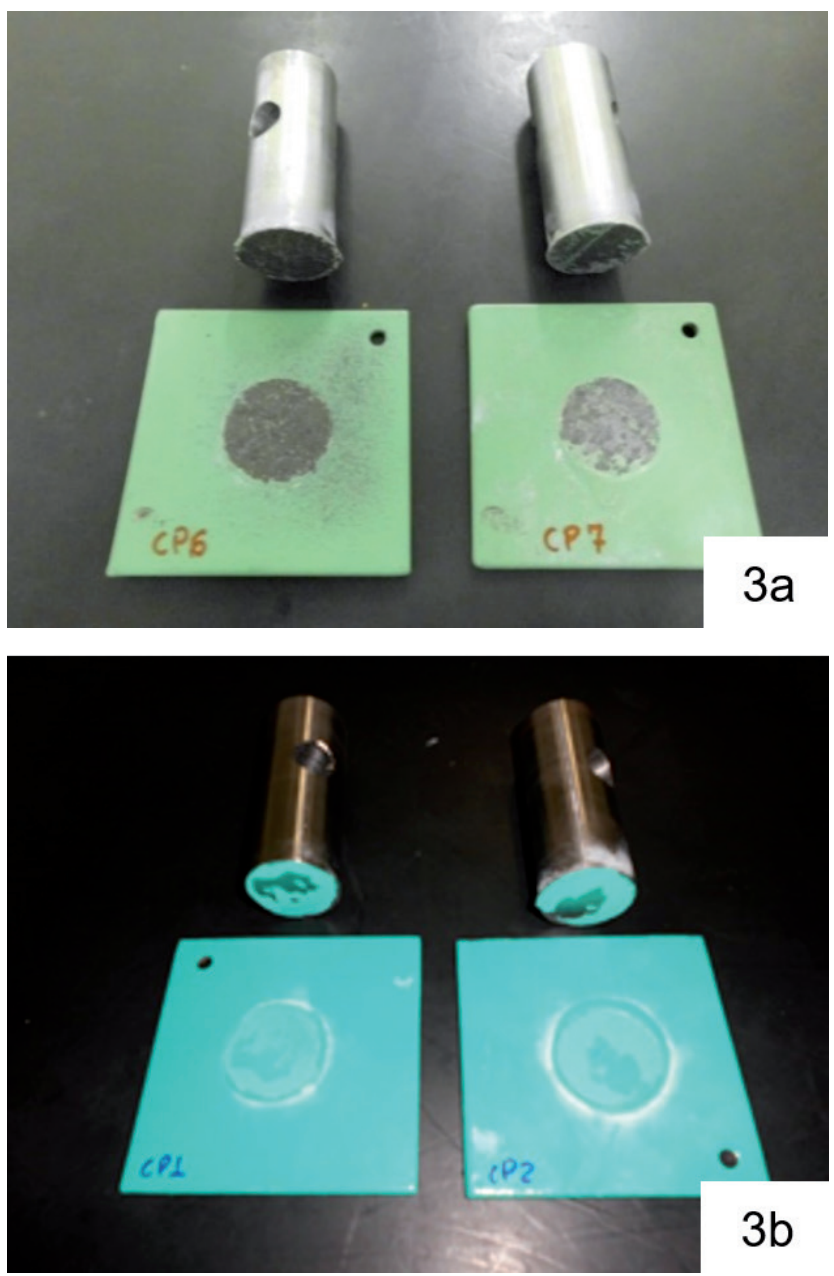

Figura 3: Amostras após ensaio de arrancamento, antes da exposição a água produzida: (a) Epóxi em pó; (b) Epóxi líquido

$\mathrm{Na}$ Figura 3 é possível visualizar a superfície das amostras com os dois tipos de aplicação (pó e líquido) após o teste de arrancamento, antes da exposição ao ensaio com água produzida. As falhas ocorridas no teste de pull off podem ser adesivas ou coesivas. Em ocorrendo uma falha adesiva a tinta pode ser totalmente ou parcialmente destacado do substrato. 
A falha coesiva por sua vez ocorre quando a tinta não é destacada, o rompimento ocorre dentro da própria camada de tinta ${ }^{23}$. Observa-se que o arrancamento na amostra com epóxi aplicado em pó (3a) e na amostra com epóxi aplicado na forma líquida (3b) ocorrem através de uma falha adesiva.

No entanto, em recobrimentos com resina epóxi contendo partículas, estudos mostram que a presença de pequenas partículas tende a ocupar pequenos vazios formados por retração local durante a cura da resina epóxi e atuam como uma ponte interconectando moléculas. Isso resulta em menor volume livre, aumentando a densidade da reticulação do polímero, o que melhora a adesão. Isto pode justificar os melhores resultados obtidos com o epóxi na forma de pó ${ }^{24-26}$.

Para aplicações de recobrimentos epóxi na forma líquida, a literatura indica que a aplicação de tintas pode resultar em uma metodologia de aplicação com pouca uniformidade e reprodutibilidade, resultando em um acabamento superficial factível a proporcionar falhas na adesão entre os materiais ${ }^{2}$.

Quando submetidas em água produzida, os valores de tensão diminuíram significativamente, sendo que as amostras com epóxi em pó foram mais influenciadas pelo meio. No entanto, apenas nas amostras onde foi aplicado o revestimento líquido que observou-se sinais de corrosão pontuais. Segundo Zhang et al., ${ }^{27}$ a presença de água no ambiente deteriora as propriedades térmicas e mecânicas das resinas epóxi utilizadas como revestimento, assim como pode contribuir no início do processo de corrosão do substrato, delaminar o revestimento e destruir a aderência.

\section{CARACTERIZAÇÃO TÉRMICA}

As amostras de epóxi foram submetidas ao ensaio de DSC. Na Figura 4 observou-se em detalhe a mudança de linha de base caracterizando a temperatura de transição vítrea ( $\mathrm{Tg}$ ) das amostras. A amostra de epóxi em pó apresentou uma menor $\operatorname{Tg}\left(60,5^{\circ} \mathrm{C}\right)$ quando comparada a amostra na forma líquida $\left(107,4^{\circ} \mathrm{C}\right)$. O que pode indicar que a amostra em pó tem o processo de gelificação (início do processo de cura) em temperaturas menores que a amostra líquida. Este comportamento pode justificar os melhores resultados nas propriedades de adesão do epóxi em pó. O pré aquecimento a temperatura de $100^{\circ} \mathrm{C}$ durante a preparação das amostras foi suficiente, nesta amostra, para iniciar a formação de ligações cruzadas, melhorando o ancoramento entre o revestimento e o substrato. Segundo Costa et al. ${ }^{28}$ após a gelificação, a mobilidade das cadeias poliméricas é reduzida devido ao aumento da densidade de ligações cruzadas, o que melhora as propriedades mecânicas do material.
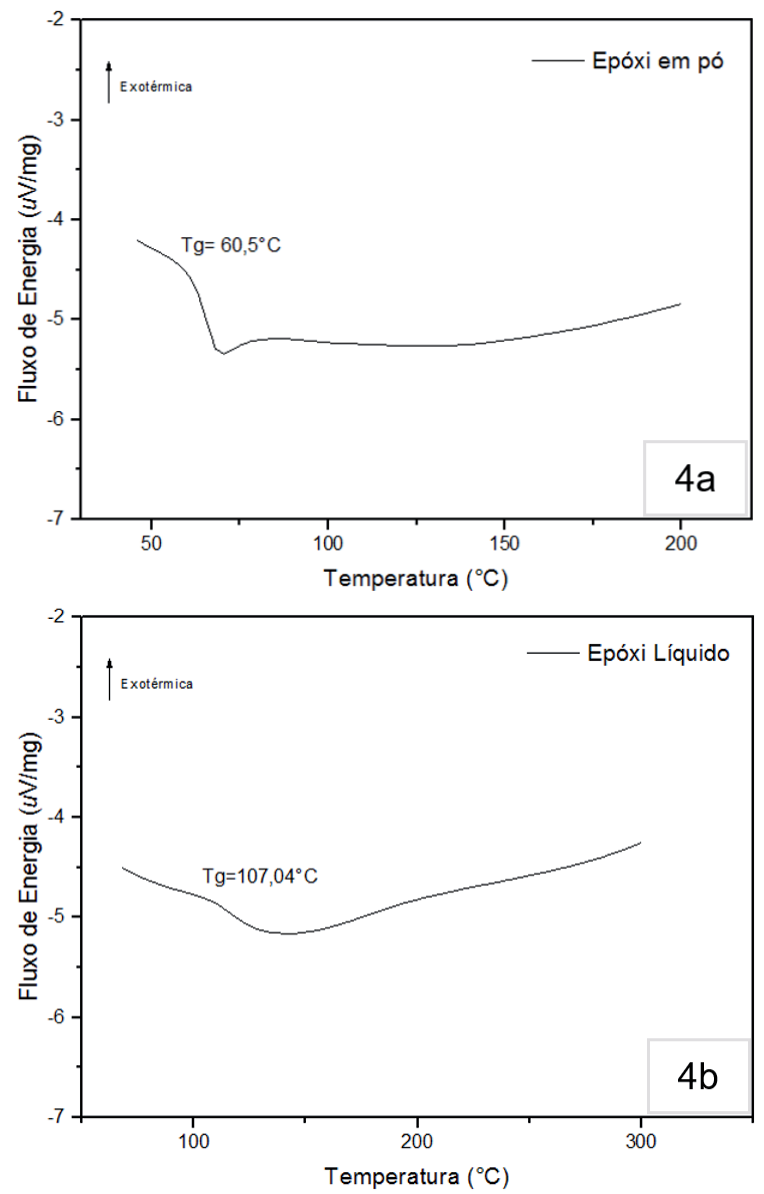

Figura 4: Curva DSC dos revestimentos. Detalhe da temperatura de transição vítrea (Tg): (a) Epóxi em pó; (b) Epóxi líquido

A Figura 5 mostra as curvas de perda de massa em função da temperatura para as amostras de revestimento epóxi em pó e líquido. Observa-se que o epóxi em pó 
apresenta maior estabilidade térmica, a perda de massa desta amostra inicia-se em $278,7^{\circ} \mathrm{C}$ enquanto que no epóxi líquido a perda de massa é iniciada em $103,4^{\circ} \mathrm{C}$.

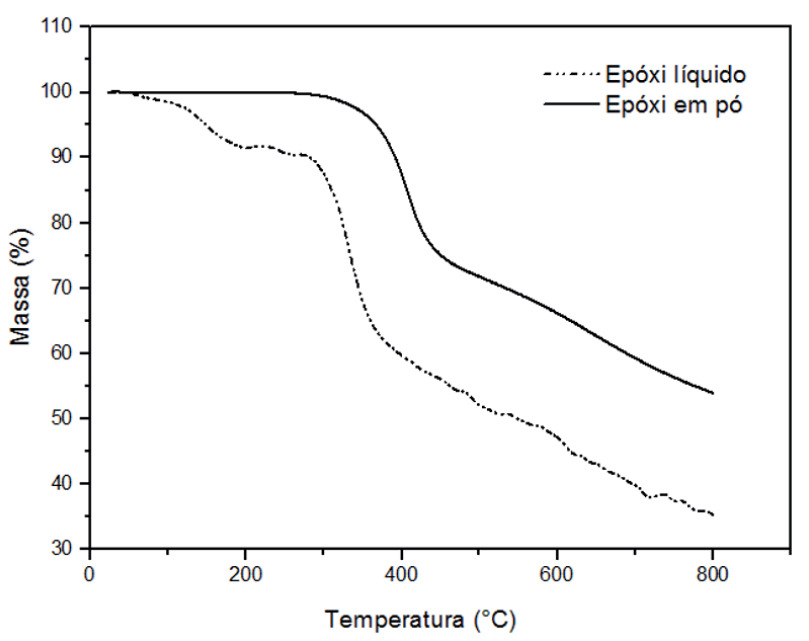

Figura 5: Curvas TG dos revestimentos epóxi em pó e líquido

O epóxi em pó apresenta dois eventos de perda de massa. O primeiro evento, ocorre entre 278,7 e $494,2^{\circ} \mathrm{C}$. Observa-se, neste evento, uma perda de massa de $27,7 \%$ que acontece em uma taxa de decomposição de $1,3 \% / \mathrm{min}$. Um segundo evento de perda de massa, de $14,1 \%$ é observada entre 494,2 e $737,2^{\circ} \mathrm{C}$. A literatura indica que a perda de massa do epóxi está associada a eliminação de água, solventes e em maiores temperaturas a decomposição de segmentos de cadeia na estrutura reticulada da resina polimérica ${ }^{29-30}$.

$\mathrm{Na}$ amostra de epóxi líquido são observados quatro eventos de perda de massa. Inicialmente, nos eventos I e II, é observada a eliminação de água e solventes entre 103,4 e $284,7^{\circ} \mathrm{C}$. A partir de $284,7^{\circ} \mathrm{C}$ ocorre a maior percentual de perda de massa de $54,4 \%$, a partir desta temperatura o polímero já sofre reticulação e assim a degradação observada deve-se a decomposição dos segmentos reticulados ${ }^{31-32}$.

\section{Conclusão}

Pode-se verificar que o tipo de aplicação do revestimento (pó ou líquido) tem influência direta nas propriedades térmicas e adesivas do substrato. Verificouse que o revestimento na forma em pó apresentou melhor adesão, resultando em melhores propriedades no teste de arrancamento. Os testes em água produzida mostraram que os revestimentos não são eficientes neste ambiente. Através da caracterização térmica dos revestimentos, pode-se verificar que o epóxi na forma em pó apresenta melhor estabilidade térmica e o processo de reticulação neste material inicia-se em temperaturas menores que o revestimento na forma líquida.

\section{Agradecimentos}

A empresa Nova Coating e ao Centro Universitário SENAI CIMATEC.

\section{Referências}

1. Roberge, Pierre R. Handbook of corrosion engineering. McGrawHill, 1999.

2. Ferreira, M., Camargo Jr, S. S., Barbosa, B. M., Gomes, R. V., Lachtermacher, M. G., \& Quintela, J. Propriedades mecânicas de epóxis utilizadas no recobrimento interno de oleodutos e gasodutos. Polímeros, 2002, 12(3), 180-187.

3. Henriques, C. C. D., IX Seminário Brasileiro de Aço Inoxidável. Palestra: Desafios na seleção de materiais na indústria do petróleo [acesso em 12 jan 2015]. Disponível em: http://www.nucleoinox. org.br/upfiles/arquivos/downloads/apresent_petrobras_desafios_ sele $\%$ C3\%A7\%C3\%A3o_materiais_v2.pdf.

4. Piper, H., Barbosa, J. D. V., Melo, P. D. S., Silva, E., \& Azevedo, J. B. Influência do processo de cura nas características mecânicas e térmicas de revestimentos poliméricos a base de resina epóxi. In: $8^{\circ}$ Congresso Brasileiro de Engenharia de Fabricação, Salvador - BA, 2015.

5. Riaz, U., Nwaoha, C., \& Ashraf, S. M. Recent advances in corrosion protective composite coatings based on conducting polymers and natural resource derived polymers. Prog. Org. Coat., 2014, 77(4), 743-756. https://doi.org/10.1016/j.porgcoat.2014.01.004. 
6. Moreira, W., "Compósito I", In: Associação Brasileira de Materiais Compósitos, Brasil, 2009.

7. Buch, X., \& Shanahan, M. E. R. Migration of cross-linking agents to the surface during ageing of a structural epoxy adhesive. Int. J. Adhes. Adhes., 2003; 23(4), 261-267.0.1016/S0143-74963)00028-9.

8. Guermazi, N., Elleuch, K., \& Ayedi, H. F.The effect of time and aging temperature on structural and mechanical properties of pipeline coating. Materials \& Design, 2009; 30(6), 2006-2010. https://doi.org/10.1016/j.matdes.2008.09.003.

9. Wouters, M., Craenmehr, E., Tempelaars, K., Fischer, H., Stroeks, N., \& van Zanten, J. Preparation and properties of a novel remendable coating concept. Prog. Org. Coat., 2009; 64(2-3), 156162. https://doi.org/10.1016/j.porgcoat.2008.09.023.

10. Brostow, W., Dutta, M., \& Rusek, P. Modified epoxy coatings on mild steel: tribology and surface energy. Eur. Polym. J., 2010;46(11), 2181-2189. https://doi.org/10.1016/j.eurpolymj.2010.08.006.

11. Ionashiro, M. G.; Fundamentos da termogravimetria, análise térmica diferencial, calorimetria exploratória diferencial. Araraquara, São Paulo, Editora: Giz editorial, 2004.

12. Amini, S., Mowla, D., Golkar, M., \& Esmaeilzadeh, F. Mathematical modelling of a hydrocyclone for the down-hole oil-water separation (DOWS). Chem. Eng. Res. Des., 2012; 90(12), 2186-2195.

13. Piper, H., Barbosa, J. D. V., Melo, P. D. S., Silva, E., Azevedo, J. B \& Santos, E. S. Caracterização Térmica de Revestimentos Internos a Base de Epóxi Utilizados em Tubulações de Aço Carbono. In: Congresso Nacional de Engenharia Mecânica, Fortaleza- CE, 2016.

14. Thomas, J. E; Triggia, A. A.; Correia, C. A., Fundamentos de engenharia de petróleo. Ed. Interciência, Petrobras, Rio de Janeiro, RJ, 2001.

15. Fakhru'l-Razi, A., Pendashteh, A., Abdullah, L. C., Biak, D. R. A., Madaeni, S. S., \& Abidin, Z. Z. Review of technologies for oil and gas produced water treatment. J. Hazard. Mater., 2009; 170(2-3), 530-551. https://doi.org/10.1016/j.jhazmat.2009.05.044

16. Novacoating: Quadro Geral de Produtos Nova Coating. [acesso em 20 nov 2018]. Disponível em: http://novacoating.com.br/wp-content/ uploads/2015/05/NC_QuadroGeralProdutos.pdf. Acessado em Novembro 2018.

17. Norma, N. A. C. E. N $\mathrm{N}^{\circ}$ /SSPC-SP 10, Near white blat cleaning, Houston, USA (2010).

18. ASTM-D4541, Pull-Off Strength of Coatings Using Portable Adhesion Testers, USA, 2009.
19. Motta, A. R. P. D., Borges, C. P., Kiperstok, A., Esquerre, K. P., Araujo, P. M., \& Branco, L. D. P. N. Tratamento de água produzida de petróleo para remoção de óleo por processos de separação por membranas: revisão. Engenharia Sanitária e Ambiental, 2013; 18(1), 15-26. http://dx.doi.org/10.1590/S1413-41522013000100003.

20. Gentil, V. Corrosão, 6 ed., LTC: Livro Técnico e Científicos SA, Rio de Janeiro, 2011.

21. Nyborg, R., CO2 Corrosion Models for Oil and Gas Production Systems. Nace Corrosion Conference, Paper 10307, 2010.

22. Dugstad, A.; Lunde L.; Nesic S., Prevention on Pipeline Corrosion Conference. Institutt for Energiteknikk, Kjeller,Houston, Texas,1994

23. Serenário, Maria Eduarda Dias et al. Estudo das propriedades da tinta epóxi-Nb2O5 aplicada na indústria química. Revista Virtual de Química, 2019, v. 11, n. 1, p. 218-236.

24. Shi, X., Nguyen, T. A., Suo, Z., Liu, Y., \& Avci, R. Effect of nanoparticles on the anticorrosion and mechanical properties of epoxy coating. Surf. Coat. Technol., 2009: 204(3), 237-245. https:// doi.org/10.1016/j.surfcoat.2009.06.048

25. Bagherzadeh, M. R., \& Mousavinejad, T. Preparation and investigation of anticorrosion properties of the water-based epoxyclay nanocoating modified by Na+-MMT and Cloisite 30B. Prog. Org. Coat., 2012: 74(3), 589-595. https://doi.org/10.1016/j. porgcoat.2012.02.006.

26. Bertuoli, P. T., Frizzo, V. P., Piazza, D., Scienza, L. C., \& Zattera, A. J. Caracterização mecânica e de proteção à corrosão do aço carbono revestido com tinta em pó base epoxi contendo montmorilonita funcionalizada com silano. Tecnologia em Metalurgia, Materiais e Mineração,2014: 11(2), 180. http://dx.doi.org/10.4322/tmm.2014.026.

27. Zhang, S. Y., Ding, Y. F., Li, S. J., Luo, X. W., \& Zhou, W. F. Effect of polymeric structure on the corrosion protection of epoxy coatings. Corros. Sci., 2002: 44(4), 861-869. https://doi.org/10.1016/ S0010-938X(01)00091-9

28. COSTA, M. L., REZENDE, M. C., PARDINI, R. L. C. "Métodos de estudo de cinética de cura de resinas epóxi.". Polímeros: Ciência e Tecnologia., 1999, Abr/Jun, pp. 37-44. http://dx.doi.org/10.1590/ S0104-14281999000200011

29. Dai, Z., Li, Y., Yang, S., Zong, C., Lu, X., \& Xu, J. Preparation, curing kinetics, and thermal properties of bisphenol fluorene epoxy resin. J. Appl. Polym. Sci., 2007: 106(3), 1476 1481. https://doi. org/10.1002/app.26585

30. Wang, X., \& Zhang, Q. Synthesis, characterization, and cure properties of phosphorus-containing epoxy resins for flame 
retardance. Eur. Polym. J., 2004: 40(2), 385-395. https://doi. org/10.1016/j.eurpolymj.2003.09.023

31. Rosu, D., Cascavaf, C. N., Ciobanu, C., \& Rosu, L. An investigation of the thermal degradation of epoxy maleate of bisphenol A. J. Anal. Appl. Pyrolysis, 2004: 72(1), 191-196. https://doi.org/10.1016/j. jaap.2004.05.002

32. Camino, G., Tartaglione, G., Frache, A., Manferti, C., \& Costa, G. Thermal and combustion behaviour of layered silicate-epoxy nanocomposites. Polym. Degrad. Stab. 2005: 90(2), 354-362. https://doi.org/10.1016/j.polymdegradstab.2005.02.022

\section{Helmut Piper*1, Josiane D. V. Barbosa', Joyce B. Azevedo² \& Pollyana S. M. Cardoso'}

${ }^{1}$ Centro Universitário SENAI CIMATEC - Av. Orlando Gomes, 1845 - Piatã CEP: 41650-010, Salvador, BA

${ }^{2}$ Universidade Federal do Recôncavo da Bahia - Av. Centenário, 697 - Sim CEP:44042-280, Feira de Santana - BA

*E-mail: hpiper@uol.com.br. 